\title{
Measurement of 5-eV Atomic Oxygen Using Carbon Based Films: Preliminary Results
}

\author{
Carl B. White, Graham T. Roberts, and Alan R. Chambers
}

\begin{abstract}
Carbon-based sensors have been developed to measure the atmospheric neutral atomic oxygen (AO) flux experienced by spacecraft in low Earth orbit. Thin- and thick-film carbon sensor elements were deposited onto an alumina substrate between thick-film gold tracks and silver palladium solder pads. AO flux is deduced by measuring resistance changes as the carbon film erodes and applying a simple theory. A wide range of responses were observed that are dependent on the deposition process and post deposition annealing. The deposition methods used were dc magnetron sputtering, e-beam evaporation, and screen-printing. The sensors tested compare favorably with similar silver-based sensors that have been flown previously on small satellite missions with significant mass/power constraints.
\end{abstract}

Index Terms-Atomic oxygen (AO), carbon, sensing, sensor.

\section{INTRODUCTION}

A T altitudes between $180-700 \mathrm{~km}$, atomic oxygen (AO) is the most abundant atmospheric species that, being highly reactive, can cause certain materials to degrade [1]. It is, therefore, important to monitor the $\mathrm{AO}$ environment experienced by spacecraft operating at these altitudes.

The sensors described here measure AO flux or time integrated flux (fluence) by monitoring in situ changes in electrical resistance across a film of susceptible material. As the film degrades upon $\mathrm{AO}$ exposure, the measured resistance increases. By calibrating the sensors in ground based simulation facilities, $\mathrm{AO}$ concentrations in low-Earth orbit (LEO) can be measured. This method of sensing provides significant mass/power benefits when compared with other sensing techniques [2], so are well suited to small satellite missions. Suitable AO sensing materials include silver, zinc oxide and carbon [3].

Previous work with silver films showed some restrictions brought about by the development of a protective oxide layer as the material reacts with $\mathrm{AO}$ [2]-[4].

Other devices based on regenerative semi-conducting zinc-oxide films have hysteresis limitations, require extensive data manipulation to obtain flux values [5] and are inherently

Manuscript received February 17, 2004; revised July 8, 2004. This work was supported by the Engineering and Physical Sciences Research Council under Grant GR/R26009/01. The associate editor coordinating the review of this paper and approving it for publication was Dr. Giorgio Sberveglieri.

C. B. White is with the Astronautics Research Group, University of Southampton, Highfield, Hants SO17 1BJ, U.K. (e-mail: c.b.white@ soton.ac.uk).

G. T. Roberts is with the Aerodynamics and Flight Mechanics Research Group, University of Southampton, Highfield, Hants SO17 1BJ, U.K. (e-mail: gtr@ soton.ac.uk).

A. R. Chambers is with the Materials Research Group, University of Southampton, Highfield, Hants SO17 1BJ, U.K. (e-mail: a.r.chambers@ soton.ac.uk).

Digital Object Identifier 10.1109/JSEN.2005.858973 unsuitable for material characterization purposes, since $\mathrm{AO}$ measurement is interrupted as the sensor is regenerated.

Carbon film sensors are based on a similar operational principle as those with silver: Ideally, as the sensors chemically react with $\mathrm{AO}$, the carbon will erode to give a simple measurable change in resistance. Unlike silver sensors, the carbon response is not dependent on diffusion mechanisms brought about by an oxide layer, as carbon reaction products $\left(\mathrm{CO}\right.$ or $\left.\mathrm{CO}_{2}\right)$ are volatile.

\section{THEORETICAL ASPECT}

\section{A. Ideal In Situ Resistance Measurements}

Although much work has been carried out on eroding film AO sensors [10]-[13], none have described a method to compare different carbon deposition techniques, an important consideration given the variety of techniques available.

For sensor comparison and calibration purposes, a proposed theory of operation is given below, which is based on a film erosion mechanism and constant resistivity. To easily compare sensor materials with different $\mathrm{AO}$ responses, the ratio of initial resistance and measured resistance is taken

$$
\frac{R_{0}}{R}=\frac{\rho \frac{L}{A_{0}}}{\rho \frac{L}{A}}
$$

where $R_{0}=$ initial resistance $(\Omega), R=$ resistance $(\Omega), A_{0}=$ initial cross-sectional area $\left(\mathrm{cm}^{2}\right), A=$ cross-sectional area $\left(\mathrm{cm}^{2}\right), L=$ length of carbon film $(\mathrm{cm})$, and $\rho=$ film resistivity $(\Omega \cdot \mathrm{cm})$.

By assuming a square sensor, and constant resistivity it can be shown that

$$
\frac{R_{0}}{R}=\frac{A}{A_{0}}=\frac{\tau W}{\tau_{0} W}=\frac{\tau}{\tau_{0}}
$$

where $\tau_{0}=$ initial thickness $(\mathrm{cm}), \tau=$ thickness $(\mathrm{cm})$, and $W=$ film width $(\mathrm{cm})$.

The eroded volume can be estimated from

$$
\Delta V=W L\left(\tau_{0}-\frac{R_{0} \tau_{0}}{R}\right)
$$

where $\Delta V=$ volume change by erosion $\left(\mathrm{cm}^{3}\right)$

Erosion yield is then described by

$$
Y=\frac{\Delta V}{\mathrm{FWL}}
$$

where $\mathrm{F}=\mathrm{AO}$ fluence $\left(\right.$ atoms $\left./ \mathrm{cm}^{2}\right)$ and $Y=$ erosion yield $\left(\mathrm{cm}^{3} /\right.$ atom).

It can be shown from above that fluence is given by

$$
F=-\frac{\tau_{0}}{Y} \frac{R_{0}}{R}+\frac{\tau_{0}}{Y} .
$$


TABLE I

Carbon Material Depositions and Atomic OXYgen EXPosures

\begin{tabular}{|c|c|c|c|c|c|}
\hline $\begin{array}{l}\text { Deposition } \\
\text { process }\end{array}$ & Deposition Parameters & $\begin{array}{l}\text { Post Deposition } \\
\text { Heat Treatment }\end{array}$ & $\begin{array}{c}\text { Initial Film } \\
\text { Resistivity } \\
(\Omega . \mathrm{m})\end{array}$ & $\begin{array}{c}\text { Sensor } \\
\text { Identification }\end{array}$ & $\begin{array}{l}\text { Exposure } \\
\text { Run No. }\end{array}$ \\
\hline \multirow[t]{4}{*}{$\begin{array}{l}\text { Screen } \\
\text { Printing }\end{array}$} & Du Pont 4232 & $\begin{array}{c}\text { Dry at } 170^{\circ} \mathrm{C} \text { for } 3 \\
\text { minutes then } \\
120^{\circ} \mathrm{C} \text { cure for } 360 \\
\text { minutes }\end{array}$ & 0.066 & $\mathrm{~A}$ & $1,3^{*}$ \\
\hline & $\begin{array}{l}\text { Du Pont } 4232 \text { (double } \\
\text { deposition) }\end{array}$ & As above & 0.082 & B & 3 \\
\hline & Du Pont 4242 & As above & 4.1 & $\mathrm{C}$ & 2 \\
\hline & $\begin{array}{l}\text { Du Pont } 4242 \text { (double } \\
\text { deposition) }\end{array}$ & As above & 4.8 & $\mathrm{D}$ & 3 \\
\hline \multirow[t]{2}{*}{$\begin{array}{l}\text { Electron Beam } \\
\text { Evaporation }\end{array}$} & $\begin{array}{r}5 \mathrm{kV} \text { accelerating } \\
\text { voltage at } 300 \mathrm{~mA}\end{array}$ & None & 0.013 & $\mathrm{E}$ & 1,4 \\
\hline & & $\begin{array}{l}700^{\circ} \mathrm{C} \text { for } 15 \\
\text { minutes }\end{array}$ & 0.0000257 & $\mathrm{~F}$ & 2,4 \\
\hline \multirow[t]{3}{*}{$\begin{array}{c}\text { D.C. } \\
\text { Magnetron } \\
\text { Sputtering }\end{array}$} & $\begin{array}{l}786 \mathrm{~V} \text { at } 600 \mathrm{~mA} \text {. Power } \\
\text { Density of } 2.6 \mathrm{Wcm}^{-2}\end{array}$ & $\begin{array}{l}400^{\circ} \mathrm{C} \text { for } 360 \\
\text { minutes }\end{array}$ & 54 & G & 4 \\
\hline & & $\begin{array}{l}600^{\circ} \mathrm{C} \text { for } 100 \\
\text { minutes }\end{array}$ & 12 & $\mathrm{H}$ & 2 \\
\hline & & $\begin{array}{l}600^{\circ} \mathrm{C} \text { for } 200 \\
\text { minutes }\end{array}$ & 0.6 & I & 1 \\
\hline
\end{tabular}

Equation (5) can also be resolved for time

$$
F=f t
$$

where $f=\mathrm{AO}$ flux (atoms $/ \mathrm{cm}^{2} / \mathrm{s}$ ) and $\mathrm{t}=$ time (s).

Assuming the flux and erosion yield remains constant throughout the exposure, normalized resistance can be plotted against time as a straight line, in the ideal case.

Once real resistance changes attributable to atomic oxygen are isolated, any deviations from the straight line could indicate changes in erosion yield and/or flux; however, there are some caveats to this.

Erosion yield and resistivity have been assumed constant to simplify the theory presented because of the way in which each parameter will change is generally unknown at the time of writing. Both resistivity and erosion yield could change: Such effects as $\mathrm{AO}$ absorption, variation in film composition brought about by the deposition process, or AO bombardment may all play a role.

From the gradient term in (5), for a given set of measurement electronics, the sensitivity to AO and sensor life are dependent on the ratio of initial thickness to erosion yield $\left(\tau_{o} / Y\right)$ which is equal to the maximum possible fluence measurable.

\section{SENSOR CONSTRUCTION}

Carbon films were deposited onto Coors ADS-96R alumina substrates between screen-printed gold contacts, as shown in Fig. 1. A heating element is screen printed on the reverse side of the substrate to provide temperature control if needed for future spacecraft missions. Temperatures during AO exposure were monitored using an AD590 thermistor device. Electrical contact was made using screen-printed silver palladium solder pads.

Three different techniques were used to deposit carbon onto the substrate: screen printed (thick film) carbon, e-beam evaporated carbon, and magnetron sputtered carbon. Details of each

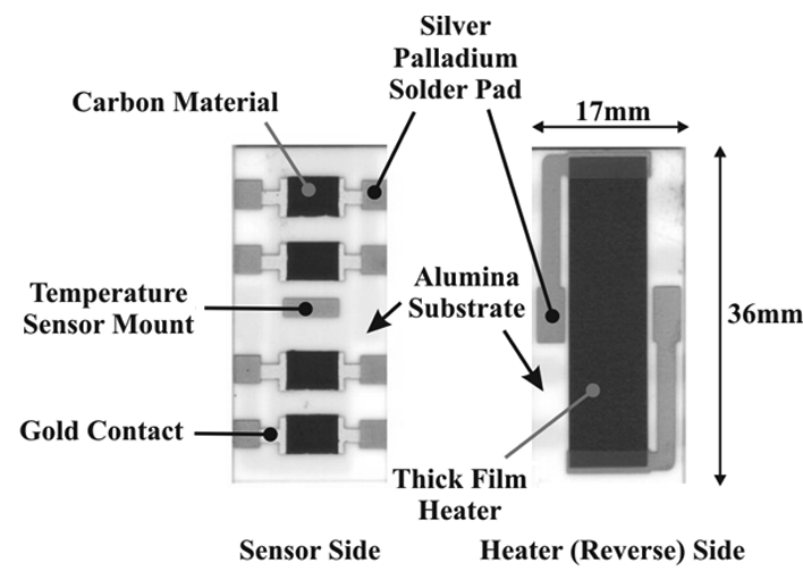

Fig. 1. Atomic oxygen sensor layout.

deposition are given in Table I. The e-beam evaporated and sputtered films were deposited from a graphitic target material, while the screen printed carbon material consists of carbon particles in a polymer paste. Unfortunately, the precise contents of the screen printed film are unknown and commercially sensitive. However, it is known that the Dupont 4232 compound has a greater carbon content than the Dupont 4242 compound.

\section{EXPERIMENTAL}

\section{A. Test Facility}

To test the response of the atomic oxygen sensors without the expense of producing a spacecraft experiment, a suitable $\mathrm{AO}$ simulation facility must be used.

All exposures were carried out in the pulsed atomic oxygen source (ATOX) at the European Space Research and Technology Centre (ESTEC), The Netherlands. The theory of operation is well documented and so shall not be described in 


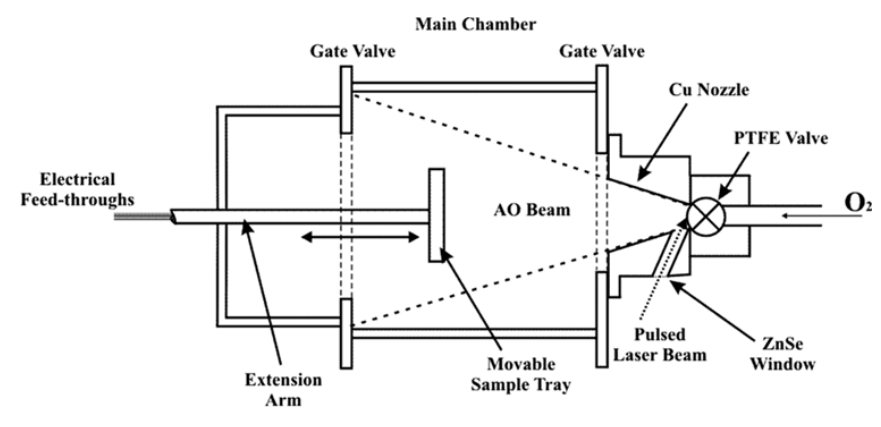

Fig. 2. ATOX facility schematic.

great detail here [6]. The basic principle consists of dissociating molecular oxygen, which is pulsed though a polytetrafluoroethylene (PTFE) valve into a copper nozzle, by use of a high-powered laser. The dissociated atoms expand through the nozzle, allowing formation of neutral atomic oxygen. The AO beam then strikes a moveable sample tray, which can be located between $55-130 \mathrm{~cm}$ from the nozzle, providing flux variations if required. The $\mathrm{AO}$ beam kinetic energy $(5 \mathrm{eV})$ is equivalent to the atoms striking a ram (forward)-facing surface of a spacecraft at LEO speeds $(\sim 8 \mathrm{~km} / \mathrm{s})$. A schematic diagram of the ATOX facility is given in Fig. 2.

One side effect of producing fast atomic oxygen in the way described is that significant amounts of ultraviolet (UV) light are also produced. This UV is also known to degrade certain spacecraft materials and can also react synergistically with AO [7]. Although UV does also exist in LEO, its proportions with respect to AO are most likely to differ from those of groundbased simulators. Therefore, the effects of UV degradation must always be considered when analysing the results. A method of isolating these effects is given in the following section.

\section{B. Measurand Isolation}

Before the sensors were exposed to an AO environment, the exposure chamber containing them first had to be pumped down to vacuum $\left(10^{-6}\right.$ mbar). During pump down the sensors (particularly the thick-film sensors) showed a change in resistance. Once pump-down was complete the sensors were heated to discover any temperature dependencies. All the sensors showed some response to temperature, which will be significant for future spacecraft applications.

Some variations in pressure and temperature during AO exposure were anticipated due to the pulsed AO beam and vacuum pumping equipment. In order to isolate resistance changes attributable to atomic oxygen from these other sources of change, two of the four sensors per substrate were covered with an alumina tablet. The alumina, being AO resistant, protects the underlying sensors from $\mathrm{AO}$ but not from the effects of vacuum or temperature.

Measuring the resistance of all sensors and using the nondimensional formulae in (7) was found to remove vacuum and temperature response from the results, assuming that the deposited material is identical for all sensors on a substrate

$$
\left(\frac{R_{0}}{R}\right)_{\mathrm{AO}}=\left(\frac{R_{0}}{R}\right)_{\text {exposed }} \times\left(\frac{R}{R_{0}}\right)_{\text {covered }} .
$$

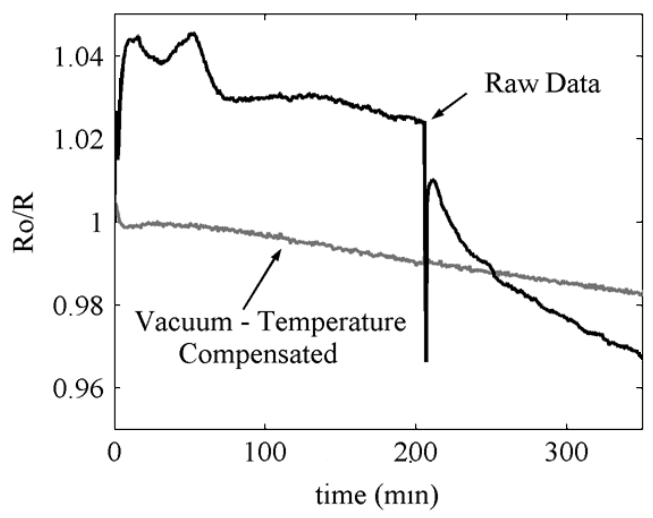

Fig. 3. Demonstration of the vacuum and temperature compensation technique used in this work.

TABLE II

ATOMIC OXYGEN EXPOSURE DATA

\begin{tabular}{ccccc}
\hline \hline $\begin{array}{c}\text { Exposure } \\
\text { Run No. }\end{array}$ & $\begin{array}{c}\text { Nozzle to } \\
\text { Sample Tray } \\
\text { Distance }(\mathrm{cm})\end{array}$ & $\begin{array}{c}\text { Kapton Witness } \\
\text { Sample Mass } \\
\text { Losses }(\mathrm{mg})\end{array}$ & $\begin{array}{c}\text { Average } \\
\text { Witness Sample } \\
\text { Fluence }\left(\mathrm{x} 10^{19}\right. \\
\left.\text { atoms } / \mathrm{cm}^{2}\right)\end{array}$ & $\begin{array}{c}\text { Time of Run } \\
\text { (minutes) }\end{array}$ \\
\hline 1 & 55 & $1.11,1.13,1.09$ & 7.9 & 360 \\
2 & 55 & $0.58,0.56,0.51$ & 3.9 & 330 \\
3 & 55 & $1.23,1,23$, & 8.8 & 688 \\
4 & $55 \rightarrow 65 \rightarrow 55$ & $0.05,0.06,0.06$ & 0.5 & 185
\end{tabular}

Fig. 3 shows two plots of normalized resistance versus time for a sputtered carbon test piece. During its exposure to AO temperature was varied using the thick-film heater, which results in relatively large changes in resistance as evident from the raw data plot. Using (7), these effects are removed, as indicated by the "vacuum-temperature compensated" line.

Further development of this method would include covering a sensor with a UV transparent film of magnesium fluoride. This setup would help identify the severity of UV degradation effects that are evident in space and in the simulation facility [14], [15]. These UV effects could then be removed from the data to isolate AO changes more effectively.

\section{Exposures}

Four main exposures were carried out during this study. Details are provided in Tables I and II.

Exposure runs 1 and 2 were designed to test each type of deposition method investigated here. In light of the results from these first two runs, run 3 was used to provide a high fluence for three different thick-film sensors. Run 4 exposed a fresh set of the most sensitive sensors tested in this programme (sensors $\mathrm{E}$ and F) and tested the remaining sensor type (sensor G). The main aim of this final run was to find out how the evaporated sensors responded to a change in AO flux. Flux variations were made by moving the sample tray from $55 \mathrm{~cm}$, to an arbitrary $65 \mathrm{~cm}$ from the nozzle. The sample tray was then moved back to $55 \mathrm{~cm}$ to check how the production of flux might have changed after the first tray movement.

The fluence of each run was determined by measuring the average pre-exposure and post-exposure mass measurements of a minimum of three Kapton witness samples (see Table II). These 


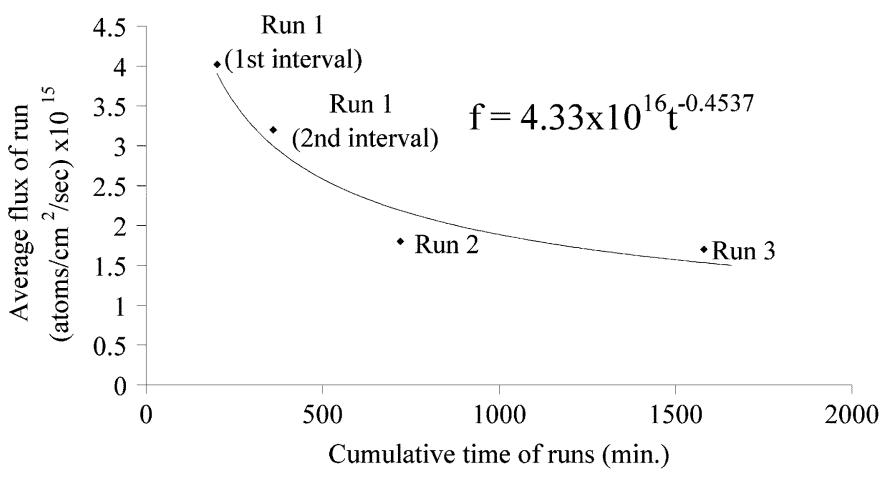

Fig. 4. Decay of atomic oxygen flux over experimental time as observed by the Kapton witness samples and (for run 1) a C-QCM.

samples were assumed to erode at a constant erosion rate of $3 \times 10^{-24} \mathrm{~cm}^{3} /$ atom [8].

While it is obviously beneficial to use a fixed nominal AO flux for each run, this could not be achieved during this experimental programme as the AO source has a natural decay in $\mathrm{AO}$ flux over time. Fig. 4 shows the decay of observed average AO flux over time during this experimental programme; a curve fit and its equation are provided for completeness. Flux was determined by dividing the Kapton witness sample fluence by the exposure time. Zero minutes indicate the commencement of run 1. It is important to note that the sample tray was moved backward during run 4 to assess the AO sensitivity of the sensors; therefore, the average flux value shown for this run is not comparable to the other runs.

A carbon-coated quartz crystal microbalance (C-QCM) was also used to take in situ fluence measurements [9]. Unfortunately, this device could not be used at the same time as AO formation due to interference from the laser. A C-QCM reading taken mid-way through exposure run 1 by temporarily switching the laser off (interval 1 in Fig. 4) suggests that the average flux reduced with time, and fell to about $80 \%$ of its initial value after a fluence of approximately $4.8 \times 10^{19}$ atoms $/ \mathrm{cm}^{2}$ (as calibrated against the Kapton witness samples). The reduction in flux was apparent from the resistance measurements obtained from the carbon film sensors, as will be shown in the following section.

\section{RESUlTS AND DisCUSSION}

\section{A. Sputtered and Thick-Film Sensors}

Fig. 5, shows the sensor response from run 1 and straight lines fitted to the data with an offset so they begin at the theoretical value of 1 . Neglecting some initial conditions and spikes attributable to ATOX source induced noise; the response of both the sputtered and screen-printed sensors initially appeared linear.

The data spike evident at approximately $205 \mathrm{~min}$ (Fig. 5) represents the switching of the breakdown laser for a C-QCM measurement. After this data point, average flux measured by the C-QCM was much reduced; a trend also noted by observing the degree of oxygen plasma glow from the facility. The apparent flux decay was also evident from the carbon films, as the data begins to deviate from the fitted straight lines. The thick-film sensors appear more sensitive to AO flux, as they deviate more from the fitted straight lines.

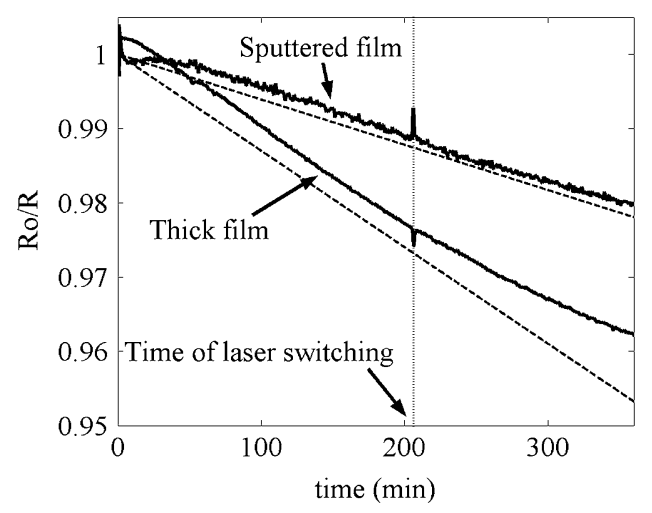

Fig. 5. Sample results from run one show the response of thick-film and sputtered film sensors.

Thickness change could not be measured because sensor erosion was smaller than the resolution of the profliometers selected for each sensor before exposures took place.

By taking line of best-fit gradients, estimates of material erosion yield have been made, assuming that the films are eroding as described earlier. The $\tau_{o} / Y$ values derived from each run are given the results summary of Table III.

The calculated erosion yields for the thick-films sensors show values between $7.27-8.51 \times 10^{-25} \mathrm{~cm}^{3}$ /atom with no obvious trends relating to the inks used; however, it must be noted that the sensors' response to the fluences in this study was generally small.

The sensors may indeed have a greater response (and trends) at greater fluences and so obviously this means that more exposures are required at greater fluences.

One potential difficulty in using the thick-film sensor for $\mathrm{AO}$ measurement is the variability of thickness. Comparing sensors A with $\mathrm{C}$ and $\mathrm{B}$ with $\mathrm{D}$ shows that there are differences (up to $19 \%$ ) in initial thickness, even though these paired samples were supposed to have nominally the same thickness. If the films are eroding, then this will obviously affect sensor life. Notice that the $\tau_{o} / Y$ ratio for sensors $\mathrm{B}$ and $\mathrm{D}$ are the same, as the differences in thickness are compensated by differences in theoretical erosion yield.

The lack of a repeatable thickness would also suggest, should subsequent depositions provide differences in erosion yield, that each sensor deposition has a unique response to AO. This outcome will inevitably mean that each individual sensor will need calibration-quite impractical when one considers the limited life of the sensor.

The sputtered samples appeared to show a potential life equivalent to the thick-film sensors, having a $\tau_{o} / Y$ ratio from 206 to 395 in the case of the sensors treated to $600{ }^{\circ} \mathrm{C}$. However, the sputtered samples are thinner than the screen-printed films and so the life is made equivalent by a lower erosion yield. As shown in Fig. 5, variations in flux were not as traceable using the sputtered samples-possibly a consequence of their lower erosion yield. Given the very small amount of theoretical erosion that has taken place, further studies with higher fluences need to be carried out to assess the true mechanisms that are taking place as the material is exposed to AO. 

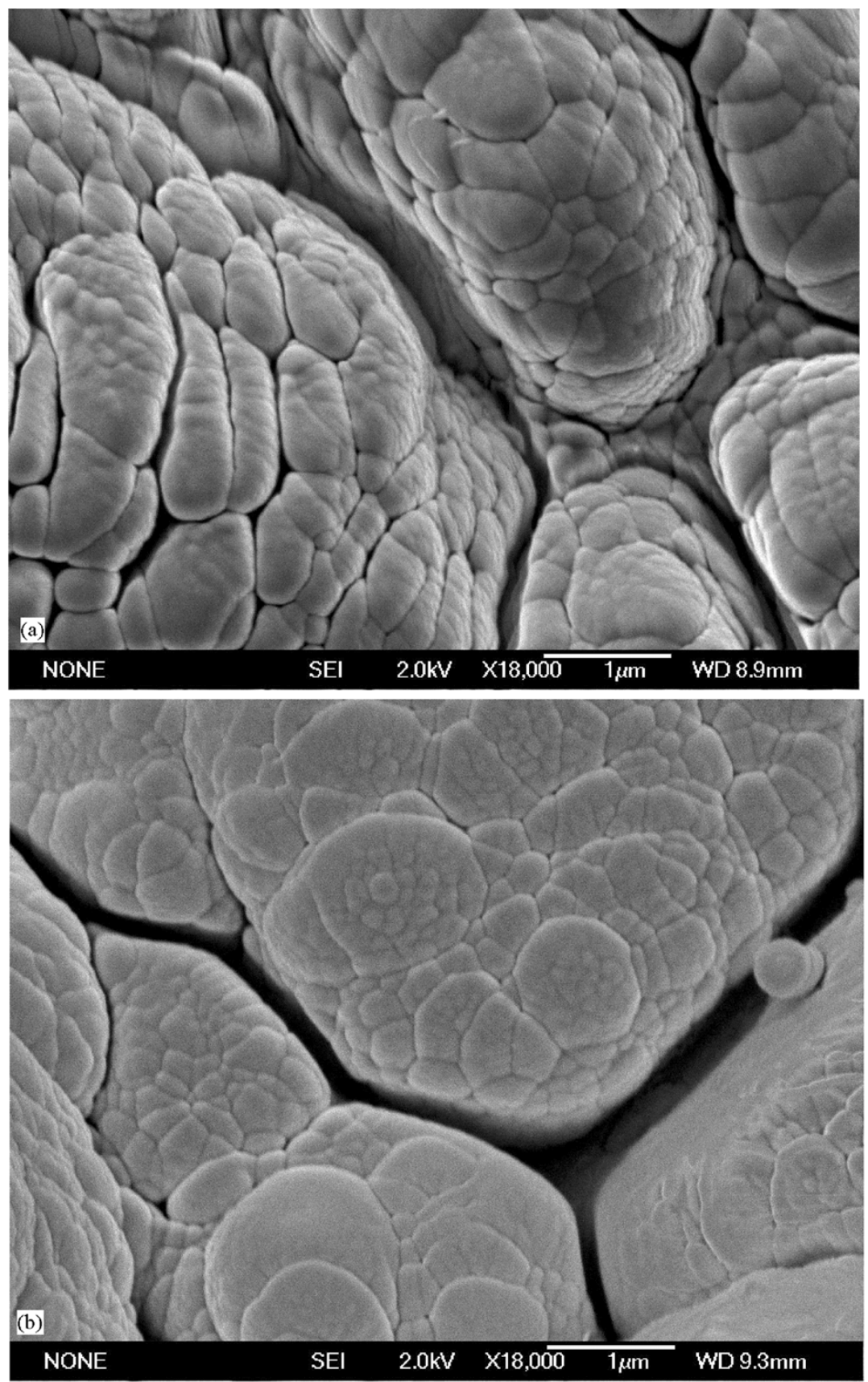

Fig. 6. Field emission gun scanning electron microscope (FEG-SEM) images of the sputtered carbon films. (a) The surface morphology of a film annealed to $600{ }^{\circ} \mathrm{C}$ for $100 \mathrm{~min}$. (b) The morphology of the film annealed to $600{ }^{\circ} \mathrm{C}$ for $200 \mathrm{~min}$.

In a similar vein to the thick-film sensors, the sputtered sensors revealed some variation in thickness. The thickness provided for all the sputtered samples shows the average and a tolerance indicating the range of thicknesses measured. The thickness variation is more significant than that recorded from the thick-film sensors, as the thickness range relative to the average thickness is much greater.

One important consideration for the sputtered films is the use of heat treatment as a method of controlling the response to atomic oxygen. Sensors H and I were stable when taking resistance measurements and show that, as anneal time increases, the sensors become less sensitive to AO. Scanning-electron microscopy reveals that this trend can be attributed to a change in film surface area during the annealing process. Fig. 6 shows the topography of the two sputtered films treated to $600{ }^{\circ} \mathrm{C}$. The sample treated for 100 min shows a very predominant and distorted "brain-like" structure, while the sample treated for double the time shows a much finer and more regulated structure.

Sensor $\mathrm{G}$ was not found to have an $\mathrm{AO}$ response and was unstable when taking resistance measurements.

\section{B. Evaporated Sensors}

Upon visual inspection of the evaporated films, it was clear that they had eroded completely after exposure to AO, except the low fluence run 4 , in which the films appeared faded. 
TABLE III

RESULTS SUMMARY

\begin{tabular}{|c|c|c|c|c|c|c|}
\hline $\begin{array}{l}\text { Deposition } \\
\text { process }\end{array}$ & $\begin{array}{c}\text { Sensor } \\
\text { Identification }\end{array}$ & $\begin{array}{l}\text { Exposure } \\
\text { Run No. }\end{array}$ & $\begin{array}{c}\text { Average Sensor } \\
\text { Initial Thickness, } \\
\tau_{0} \text { (micrometers) }\end{array}$ & $\mathrm{R}_{\mathrm{o}} / \mathrm{R}_{\text {end }}$ & $\begin{array}{c}\text { Calculated Erosion } \\
\text { Yield, Y } \\
\left(\times 10^{-25} \mathrm{~cm}^{3} / \text { atom }\right)\end{array}$ & $\begin{array}{c}\tau_{\mathrm{o}} / \mathrm{Y} \\
\left(\mathrm{x} 10^{19} \text { atom/ } \mathrm{cm}^{2}\right)\end{array}$ \\
\hline \multirow[t]{5}{*}{ Screen Printing } & A & 1 & 16.63 & 0.962 & 7.97 & 205 \\
\hline & & 3 & $15.99 *$ & $0.953^{\dagger}$ & 8.51 & 188 \\
\hline & B & 3 & 26.75 & 0.976 & 7.27 & 368 \\
\hline & $\mathrm{C}$ & 2 & 13.5 & 0.978 & 7.71 & 175 \\
\hline & $\mathrm{D}$ & 3 & 28.75 & 0.976 & 7.81 & 368 \\
\hline Electron Beam & $\mathrm{E}$ & 1 & 0.18 & 0 & 2.66 & 6.76 \\
\hline \multirow[t]{3}{*}{ Evaporation } & & 4 & & 0.82 & 6.48 & 2.78 \\
\hline & $\mathrm{F}$ & 2 & 0.18 & 0 & 15.72 & 1.15 \\
\hline & & 4 & & 0.603 & 14.29 & 1.26 \\
\hline D.C. & & & & & & \\
\hline \multirow{3}{*}{$\begin{array}{l}\text { Magnetron } \\
\text { Sputtering }\end{array}$} & G & 4 & $2.8 \pm 1.3$ & 1.000 & 0 & $\infty$ \\
\hline & $\mathrm{H}$ & 2 & $2.8 \pm 1.3$ & 0.981 & $1.36 \pm 0.63$ & 206 \\
\hline & I & 1 & $2.8 \pm 1.3$ & 0.980 & $0.71 \pm 0.33$ & 395 \\
\hline $\begin{array}{c}\text { Evaporated } \\
\text { Silver [2] }\end{array}$ & - & - & 0.169 & 0.8 & 141 & 0.12 \\
\hline
\end{tabular}

${ }^{*}$ Calculated from resistance measurements ${ }^{\dagger} \mathrm{R}_{n}$ is initial resistance of the sensors second run.

The evaporated samples showed a three-stage response upon normalizing and compensating for temperature. Sensor response begins with what appears to be a transient "settling down" of sensitivity before a linear second stage. The cause of these two stages is yet to be determined precisely, but the results would suggest that the surface of the carbon film is behaving differently to the underlying material.

The final stage, which again deviates from a linear behavior, initiates around $R_{o} / R \sim 0.3 \rightarrow 0.4$, theoretically equating to a thickness of $54 \rightarrow 72 \mathrm{~nm}$. At these thicknesses, other authors [17]-[19] have shown by various theories and experiments that as electrically conducting films become thinner, an increase in resistivity will be evident, brought about by changes in electron mobility. Therefore, the final stage is likely to be the result of increasing resistivity.

While the three-stage response does not pose a real problem if each stage is repeatable, data analysis would be made easier if the response consists of a single straight line. Accurate performance predictions based on the simple equations in Section IV could be used, rather than a more complex polynomial.

Fig. 7 shows the three-stage response for two as-deposited films (sensors E) and two films that have undergone an annealing process (sensors F). As can be seen, the relative size of each stage can vary somewhat in the case of the as-deposited films. Heat treatment has been found to make each film more alike in $\mathrm{AO}$ response as well as increasing the erosion yield of the material.

Microscopy revealed no reason for this change, but other authors [16] suggest that post-deposition annealing increases the density of the film. The reduction in film resistivity would strengthen the idea that density increases but further characterization will be required to investigate this hypothesis.

Evaporated films, with the thicknesses used here, would be more suited to low fluence missions such as high LEOs, or those missions requiring a much higher sensitivity to AO. This is a similar application of silver films [3], [4], [12] and so it is appropriate to make comparisons.

Fig. 8 shows data for an evaporated silver AO sensor adapted from other works [2] and an evaporated carbon sample. Ro/R

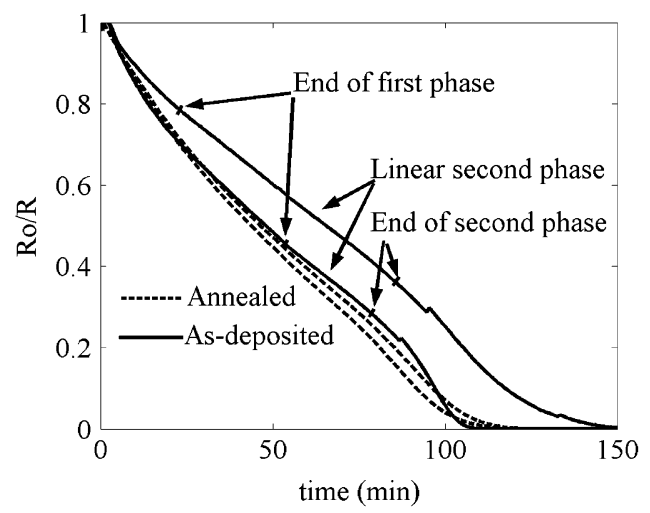

Fig. 7. Response of the evaporated carbon films from runs 1 and 2 are shown here.

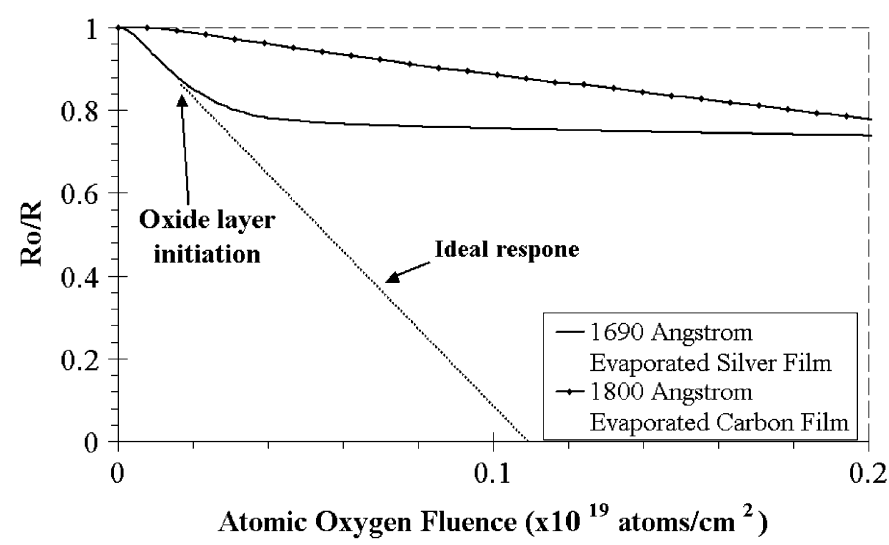

Fig. 8. Comparison of silver and carbon film response to atomic oxygen.

is shown against fluence for this comparison. Initially the silver is shown to erode very quickly as expected due to its significantly higher erosion yield. After a fluence of about $0.025 \times$ $10^{19}$ atoms $\cdot \mathrm{cm}^{-2}$, the linear oxidation rate becomes parabolic due to the continued growth of a diffusion limiting silver oxide layer [3], [4], [12].

Based on the $\tau_{o} / Y$ ratio of the silver film, the ideal response is projected down to $R_{o} / R=0$ in order to demonstrate the 


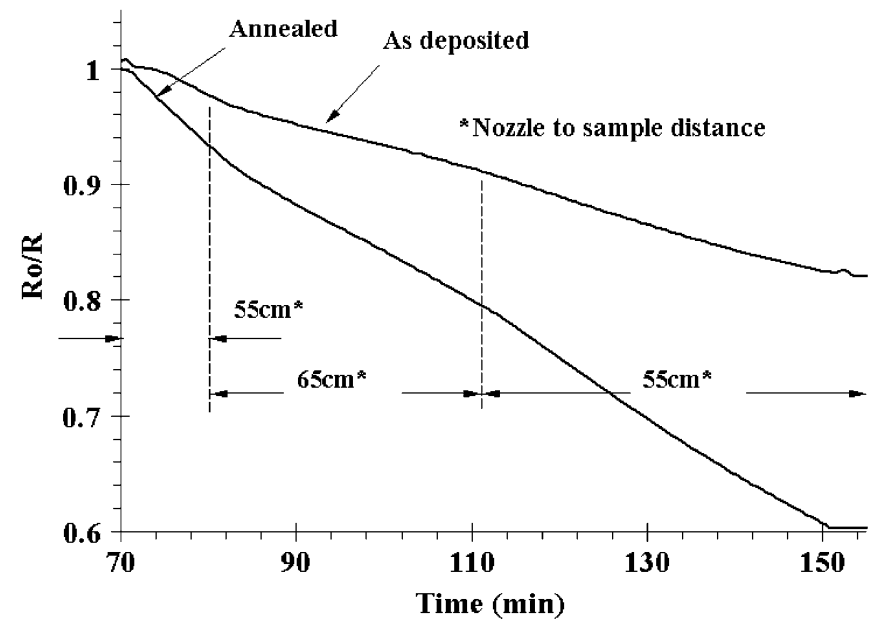

Fig. 9. Results from the evaporated sensors exposed during run 4. It can be seen that as the sample tray was moved back (to reduce AO flux) there was a slight decrease in gradient. Moving the sample tray forward to its original position increased the gradient.

amount of "lost" data brought about by the oxide layer. If evaporated carbon thicknesses are reduced to match the $\tau_{o} / Y$ ratio of silver, $\tau_{o}$ will become $17 \mathrm{~nm}$, and the sensor response will consist entirely of the final film breakdown stage, which may require a different calibration model to the one shown in (5).

Unfortunately, the flux changes observed during run 1 could not be demonstrated using the evaporated sensors, as these had already eroded completely before the flux began to decay. Some sensitivity studies were made during the final run in which the sample tray was moved from $55 \mathrm{~cm}$, back to $65 \mathrm{~cm}$, and then forward again to $55 \mathrm{~cm}$. Fig. 9 shows the normalized resistance of the two evaporated sensors during this run, where a change in gradient can be seen, suggesting that the evaporated sensors are suitable for measuring flux. Upon moving the sample tray back to $55 \mathrm{~cm}$, the gradient is different from its original value, meaning the AO flux was still decaying over time, and/or the first gradient was taken during the transient first stage described above. In general, the evaporated carbon allows a greater degree of deposition control and a wider range of thicknesses (from $100 \mathrm{~nm}$ up to a few microns) compared to the other deposition methods shown here. The only limiting factor on evaporated carbon thickness is the initial resistance value of the sensor; when resistance values fall unacceptably low either the sputtered or the thick-film sensors should be used because they have a much greater resistivity, brought about by polymeric or diamond-like additions [20].

\section{CONCLUSION}

Evaporated carbon films have a relatively complex threestage response to atomic oxygen. Heat treatment has been found to be a potential method for making the evaporated carbon response more like the linear equations described in this paper, as well as making each sensor more alike-a critical aspect of sensing.

From the low fluence runs carried out so far, the sputtered and thick-film sensors offer a simpler response to AO but further work is required to find the type of response at higher fluences.
One limitation of the work carried out so far is the absence of thickness measurement before and after AO exposure. Thickness measurements will indicate the level of accuracy of the calibration model described here, and help investigate the interactions of $\mathrm{AO}$ with the carbon material.

Careful attention must also be given to the thicknesses produced by each process. Methods must be devised for producing depositions of equal thickness, particularly in the case of sputtered and thick-film sensors.

\section{ACKNOWLEDGMENT}

The authors would like to thank the following people for invaluable support: Dr. N. Ross of Electronics and Computer Science, University of Southampton, for his guidance on electronic matters; Dr. J. Atkinson and Dr. G. Zhang, School of Engineering Sciences, University of Southampton, for their thick-film depositions; K. Lawson and Dr. J. Rao, Cranfield University School of Industrial and Manufacturing Science, for their sputtered and evaporated film depositions; and M. van Eesbeek, C. Semprimoschnig, A. Tighe, and the others at ESA-ESTEC TOS-QMC for their time and use of the ATOX facility.

\section{REFERENCES}

[1] M. R. Reddy, "Review of low earth orbit atomic oxygen on spacecraft materials," J. Mater. Sci., vol. 30, no. 2, pp. 281-307, 1995.

[2] J. J. Osborne, I. L. Harris, G. T. Roberts, and A. R. Chambers, "Satellite and rocket-borne atomic oxygen sensor techniques," Rev. Sci. Instrum., vol. 72, no. 11, pp. 4025-4041, 2001.

[3] I. L. Harris, "Space and ground-based studies of orbital atomic oxygen effects using silver film detectors," Ph.D. dissertation, School Eng. Sci., Univ. Southampton, Highfield, U.K., 1997.

[4] I. L. Harris, A. R. Chambers, and G. T. Roberts, "Preliminary results of an atomic oxygen spaceflight experiment," Mater. Lett., vol. 31, pp. 321-328, 1997.

[5] J. J. Osborne, "A Study of semiconductor-based AO sensors for ground or satellite applications," Ph.D. dissertation, School Eng. Sci., Univ. Southampton, Highfield, U.K., 1999.

[6] G. E. Caledonia, R. H. Krech, and B. D. Green, "A high flux source of energetic oxygen atoms for materials degradation studies," AIAA J., vol. 25, no. 1, pp. 59-63, 1987.

[7] S. Koontz, L. Leger, and K. Albyn, "Vacuum ultraviolet/atomic oxygen synergism in materials reactivity," J. Spacecraft Rockets, vol. 27, no. 3, pp. 346-348, 1990.

[8] E. M. Silverman, "Space environmental effects on spacecraft: LEO materials selection guide," Part 1, NASA CR 4661, p. 502, 1995.

[9] G. Drolshagen and M. Van Eesbeek, "Atomic oxygen fluence detector for BREMSAT: Scientific and technical description," in Proc. 5th ISMSE, 1991, pp. 405-408.

[10] W. R. Henderson and H. I. Schiff, "A simple sensor for the measurement of atomic oxygen profiles in the upper atmosphere," Planet. Space Sci., vol. 18, pp. 1527-1534, 1970.

[11] R. J. Thomas and D. J. Baker, "Silver film atomic oxygen sensors," Canad. J. Phys., vol. 50, pp. 1676-1681, 1972.

[12] I. L. Harris, A. R. Chambers, and G. T. Roberts, “A low cost microsatellite instrument for the in-situ measurement of orbital atomic oxygen effects," Rev. Sci. Instrum., vol. 68, no. 8, pp. 3220-3228, 1997.

[13] G. P. Miller, P. J. Pettigrew, G. N. Raikar, and J. C. Gregory, "A simple, inexpensive, hyperthermal atomic oxygen sensor," Rev. Sci. Instrum., vol. 68, no. 9, pp. 3557-3562, 1997.

[14] R. E. Smith and G. S. West, "Space and planetary environment criteria for use in space vehicle development," NASA Tech. Memo 82478, vol. 1, 1982.

[15] B. Weihs and M. V. Eesbeek, "Secondary VUV erosion effects on polymers in the ATOX atomic oxygen exposure facility," in Proc. 6th ISMSE, 1994, pp. 277-283.

[16] J. Besold, "Surface and bulk properties of electron beam evaporated carbon films," Thin Solid Films, vol. 293, pp. 96-102, 1997. 
[17] J. C. Dawson and C. J. Adkins, "Conduction mechanisms in amorphous carbon prepared by ion-beam sputtering," J. Phys.: Cond. Matter, vol. 7, no. 31, pp. 6297-6315, 1995.

[18] K. Fuchs, "The conductivity of thin metallic films according to the electron theory of metals," Proc. Cambridge Phil. Soc., vol. 34, pp. 100-108, 1938.

[19] E. H. Sondheimer, "The mean free path of electrons in metals," $A d v$. Phys., vol. 1, no. 1, pp. 1-42, 1952.

[20] C. A. Dimitriadis, N. A. Hastas, N. Vouroutzis, S. Logothetidis, and Y. Panayiotatos, "Microstructure and its effect on the conductivity of magnetron sputtered carbon thin films," J. Appl. Phys., vol. 89, no. 12, pp. 7954-7959, 2001.

Carl B. White received the M.Eng. degree in mechanical engineering from the University of Southampton, Highfield, U.K., in 2002, where he is currently pursuing the Ph.D. degree with the Astronautics Research Group.

Currently, his research is concerned with the development of carbon-based sensors for the measurement of hyperthermal atomic oxygen. Prior to this, he was responsible for the development of a reaction wheel and novel feedback system for formation flying nanosatellites.

Mr. White is currently an Associate Member of the Institution of Mechanical Engineers (IMechE) and the Institute of Physics (IOP).
Graham T. Roberts received the B.Sc. (Eng.) degree in aeronautics and astronautics from the University of Southampton, Highfield, U.K., in 1976, and the Ph.D. degree in 1985.

After spending two years as a Principal Engineer at Negretti Aviation, he returned to the University of Southampton as a Lecturer in 1986, where he is presently a Senior Lecturer with the School of Engineering Sciences. One of his main research areas concerns the simulation of the low Earth orbit (LEO) atomic oxygen environment and the measurement of the effects of high energy atomic oxygen on typical spacecraft materials. His other main research interest is concerned with high-speed (hypersonic) aerothermodynamics and heat transfer.

Alan R. Chambers received the B.Sc. and Ph.D. degrees from the University of Birmingham, Birmingham, U.K., the latter of which awarded in 1975 for his work on the wear of cemented carbide cutting tools.

Currently, he is a Senior Lecturer in the School of Engineering Sciences with the University of Southampton, Highfield, U.K... After a short period of work in industry, he returned to academic research. For 14 years, his principle research interest has been in the effects of atomic oxygen on spacecraft materials. He has been the Principal Investigator of two microsatellite missions and one International Space Station mission investigating new atomic oxygen sensing techniques. His other research interests include developing a novel form of debris/damage sensor for satellite applications, water uptake in carbon fiber composites, and wear of coatings. 